\title{
Self Evaluation for Compliance with the 12 CDIO Standards
}

\author{
George Platanitis and Remon Pop-Iliev \\ University of Ontario Institute of Technology \\ george.platanitis@uoit.ca \\ remon.pop-iliev@uoit.ca
}

\begin{abstract}
Throughout the 1980's and 1990's, collaboration began between universities, industry, and government to improve the quality and state of engineering education. Their paramount goal was to provide better ways to help students become successful engineers, possessing the necessary technical skills and expertise, exhibiting creativity, and having awareness of social, lawful, ethical, and environmental impacts as related to their profession. Traditionally, engineering programs emphasized the theoretical aspects required, while placing little emphasis on practical applications. An approach that has been introduced to provide a better learning experience for engineering students and to educate them as well-rounded engineers to be able to develop complex, value-added engineering products and processes is the CDIO (Conceive-Design-ImplementOperate) approach. This approach has been adopted by several universities within their engineering departments. At UOIT, the Mechanical Engineering curriculum has been developed around and continually evolves to line up with the goals of CDIO in terms of course and curriculum offerings for core and complementary engineering design courses, science, math, communications, engineering ethics, and humanities courses. Herein, we present an evaluation of the Mechanical Engineering program at UOIT against the twelve CDIO standards.
\end{abstract}

\section{Introduction}

Engineering programs around the world have been striving to provide graduating students with the necessary skills to become competent engineers. With accreditation boards in recent years prescribing "outcome-based" assessments of the engineering curriculum, ensuring that students gain the ability to apply knowledge of mathematics, science, and engineering science has become paramount. As such, students must be able to develop a system, component, or process to meet certain needs. With this increasing demand for knowledge application in the development of viable products, engineering design has thereby become an integral and important part of engineering curricula. These points are exemplified by Kumar, et al [1], where the authors review ABET requirements to identify barriers in incorporating sustainability in the undergraduate engineering program at Michigan Tech. Barriers include "bean counting" as opposed to process improvement (prior to ABET 2000), conventional faculty thinking, company expectations, and recruiting trends.

A recently developed approach which has been quick to be adopted by several institutes is the CDIO approach [2-4]. This approach was developed by the collaborative efforts of the Royal Institute of Technology (Sweden), Linköping University (Sweden) and the Massachusetts Institute of Technology (USA) [2, 3], which have been running a joint four-year program to develop a model for engineering education, focusing on CDIO skills. The purpose of this program is to provide students with an education that stresses fundamental engineering systems and to sustain productivity, innovation and excellence. The CDIO approach defines the levels of creating a design as follows [2]:

- Conceive - defining the need and technology, considering the enterprise strategy and regulations, developing the concept, architecture, and business case.

- Design - creating the plans, drawings, and algorithms that describe what will be implemented.

- Implement - transforming the design into the product, including manufacturing, coding, test and validation.

- Operate - using the implemented product to deliver the intended value, including maintaining, evolving and retiring the system.

Such an approach allows students, for example, to learn about conceiving a product as startup companies do, as well as exercise engineering reasoning to solve problems that are open-ended and ill-defined.

Since its inception, CDIO has been quickly adopted by institutes in Denmark (2002), Canada, South Africa, United Kingdom, and the USA (2003) in 
their engineering programs [5]. Three goals have been determined for the CDIO endeavour:

- Master a deep working knowledge of technical fundamentals.

- Lead in the creation and operation of new products and systems.

- Understand the importance and strategic value of their future research work.

The initiative provides students with an education that stresses fundamentals in terms the four CDIO levels. Each of the four founding institutes adopted the CDIO Initiative in a variety of engineering programs: vehicle (KTH), aerospace (MIT), mechanical (Chalmers), and applied physics and electronics (LiU). For each of the four CDIO themes, program outcomes were identified for both programmatic and student experience levels Curriculum (engineering program outcomes and CDIO skills education), Teaching and Learning (active and hands-on learning, feedback and research into teaching and learning approaches), Laboratories and Workshops (building and best-use), and Assessment (identifying clear goals and outcomes, assessment of skills, and programmatic evaluation).

This paper will examine the current state of the Mechanical Engineering program at UOIT in terms of how well it lines up with the twelve CDIO standards.

\section{Background}

Industry demands, as well as rapid changes to encompassing technical and social drivers, constantly challenge engineering education. In particular, this has been noted by the chemical engineering department at University of Queensland [6]. With graduates facing increased process complexity, new processes, integrated industrial projects, and more multidisciplinary projects, changing the delivery of the engineering program to students is necessary to address these needs. Therefore, a project-centred curriculum was developed to introduce different program-wide curriculum design methods, and teaching practices to address ever-changing workplace and societal demands. In another example, curriculum integration (motivated by common grounds between subject areas) was introduced so that the chemical engineering degree better adapts to changes in the profession, including technological advances, and produces graduating students who are continually in touch with the real world [7].

Several examples exist in which the CDIO approach has been adopted by engineering programs. For instance, a CDIO approach was used as a means to establish content for an undergraduate level course in Life Cycle Engineering at several universities [8], where it was necessary to educate undergraduate students about environmental concerns, where the emphasis was on design for environment (DFE) and producing a series of recommendations for product design that would reduce the environmental impact. Factors considered included energy consumption, risk analysis, eco-design, and Global Warming.

In another example, the CDIO approach was used to improve the curriculum of the civil engineering program at Shantou University [9, 10]. Starting in 2006, a design-directed curriculum was developed and put into effect, where students were put into a design environment to not only learn engineering science, technology, and non-engineering knowledge, but to be able to apply what they learned. Students also practice communication, project management, leadership, and other skills. Additionally, ethics, integrity, and professionalism are emphasized (hence, the EIP-CDIO approach [10]). One of the challenges of implementing a design-directed curriculum in a civil engineering program was the difficulty to plan operating products that fulfill design-build requirements.

The CDIO model was also used by two universities in Chile (Universidad de Chile and Pontifica Universidad Católica de Chile) [11]. First the program requirements of their respective engineering programs were analyzed, then the CDIO model was adopted to propose new models for the curricula and course content. The result was a unified syllabus that could be used as a national reference model to guide the development of the country's engineering programs.

Not only has the CDIO approach been adopted by engineering programs around the world, but by other degree programs as well. For instance, the CDIO approach was adopted by the University of Economics and Business (Vietnam National University) in Hanoi [12] to develop learning outcomes at the third level of detail, at the conceptual stage, for their economics-forforeign-affairs discipline. In another application, the communications requirement was used to form the basis of a Communication of Mathematics course [13] in which the students are exposed to more mathematics and get an opportunity to follow/present a logical argument, as well as gain experience in oral and written communication. The potential for student performance to improve in other mathematics courses, as well as other subjects in general, also exists.

In this paper, the authors present the current structure of the Mechanical Engineering program at UOIT and examine how well the curriculum lines up with the twelve CDIO standards.

\section{The CDIO Standards}

The CDIO initiative was developed to reconcile the tension between two growing needs - demand of 
graduating students to embody an increasing amount of technical knowledge, and the recognition that young engineers must possess an array of personal, interpersonal, and system building knowledge and skills [14]. As a result, the CDIO Syllabus [14, 15] was created to provide a template and process such that the Syllabus can be customized to any undergraduate engineering program.

The Syllabus summarizes formally the set of knowledge, skills, and attitudes desired of future young engineers desired by industry, alumni, and academia, setting clear, complete and consistent goals for undergraduate engineering education that are well understood and can be implemented by engineering faculty $[14,15]$. The four parts of the Syllabus each encompass the four expectations of engineering graduates [15]:

- Part 1 - Technical Knowledge and Reasoning.

- Part 2 - Personal and Professional Skills and Attributes.

- Part 3 - Interpersonal Skills.

- Part 4 - Conceiving, Designing, Implementing, and Operating Systems in the Enterprise and Societal Context.

In January 2004, the CDIO Initiative adopted 12 standards to describe CDIO programs [16], and serve four purposes:

- Define distinguishing features of a CDIO program.

- Serve as guidelines for educational program reform and evaluation.

- Create benchmarks and goals with worldwide application.

- Provide a framework for continuous improvement.

The twelve CDIO standards are:

Std. 1 - CDIO as a context (program philosophy) for engineering education.

Std. 2 - CDIO Syllabus outcomes (learning outcomes for graduating engineers and their validation by key stakeholders).

Std. 3 - Integrated curriculum, designed with mutually supporting subjects.

Std. 4 - Introduction to Engineering

Std. 5 - Design-build experiences (basic and advanced level)

Std. 6 - CDIO workspace to support hands-on learning.

Std. 7 - Integrated learning experiences to acquire disciplinary knowledge, personal, interpersonal, product and system building skills.

Std. 8 - Active learning, based on active experiential learning methods.

Std. 9 - Enhancement of faculty CDIO skills.

Std. 10 - Enhancement of faculty teaching skills.
Std. 11 - CDIO skills assessment.

Std. 12 - CDIO program evaluation.

\section{Mechanical Engineering at UOIT}

At UOIT, students entering the engineering program have a choice of three mechanically-oriented engineering fields - Mechanical Engineering (with a choice of Comprehensive, Energy, or Mechatronics specialization), Manufacturing, and Automotive. All three fields contain common subject areas in mathematics, chemistry, physics, statics and dynamics, economics, thermodynamics, fluid mechanics, communications, environmental sciences, as well as humanities, law, ethics, and professionalism. Each field also has common core design courses which include design-build components of various levels of difficulty, as well as program specific design courses (for example, Advanced Mechatronics in the Mechatronics option). In their third year, students begin taking more specific courses to their chosen specializations. By their fourth year, students' programs consist of courses almost entirely specific to their respective fields, including their programspecific capstone courses. The question, though, is how well does the Mechanical Engineering program line up with the twelve CDIO standards?

\section{Evaluation of UOIT's Mechanical Engineering Program against CDIO Standards}

The Mechanical Engineering programs at UOIT are continually evolving to line up with the goals of CDIO in terms of course and curriculum offerings for core and complementary engineering design courses, science, math, communications, engineering law and ethics, and humanities courses. Herein, we evaluate the Mechanical Engineering program for each of the twelve standards to see how well the program and its streams line up with the CDIO standards.

Standard 1 - At this point, a mission statement or approved documentation is needed to help officially recognize the Mechanical Engineering program as a CDIO program.

Standard 2 - Through core, complementary, and program specific courses, students learn various mathematics, science, engineering, interpersonal, teamwork, and communication skills, along with knowledge in engineering business, societal impact, law, and ethics, which they ultimately apply to the design, development, implementation and operation of a product for its entire lifecycle.

Standard 3 - The Mechanical Engineering program is fully integrated with both technical and non-technical 
learning as applied to the engineering field, and includes design-build group projects shared across multiple courses. Examples include the integrated design project of third-year Computer-Aided Design with Kinematics and Dynamics of Machines, where students design a system by applying skills learned in both courses (CAD design, and kinematic and dynamic analysis, simulation, and validation) as well as capstone design groups/projects spread across multiple disciplines.

Standard 4 - All Mechanical Engineering fields have a common first-year curriculum, in which students are introduced to applicable mathematics, science, humanities, and communication skills, and are introduced to the concept of engineering design and development.

Standard 5 - Students are afforded the opportunity to take core and complementary courses requiring them to engage in design-build projects (individually and in groups), which increase in level of difficulty each year, from a simple design-build and feasibility analysis in first-year to full product lifecycle considerations at the capstone level. Engineering programs at UOIT also offer an internship program (12-16 month placement) following third-year, as well as co-op program (3-4 month placement) to provide students with co-curricular experiences in engineering $[17,18]$.

Standard 6 - Several facilities equipped with the latest tools and technologies are readily available to support hands-on learning for engineering students. These include the Integrated Engineering Design Centre, a Component Design Laboratory, the Energy Centre, a Solid Mechanics and Materials Laboratory, a Dynamics, Kinematics and Vibrations Laboratory, a Manufacturing Laboratory, and the Borehole Thermal Energy Storage Laboratory. An Integrated Manufacturing Centre is also a key laboratory to facilitate advanced learning in manufacturing, mechatronics, and engineering. Finally, mechanical, automotive, and manufacturing students have access to an engineering design laboratory and a computeraided design laboratory, equipped with workstations containing various $\mathrm{CAD}$ and analysis tools to facilitate the engineering design process and enhance student learning.

Standard 7 - In addition to technical knowledge, students are required to take a course dealing with science and technological impacts on society (for example, environmental and economic impacts), challenging them to critically think of remediation measures for existing problems and for the prevention of future problems. This course is taken during firstyear. Also, students learn about technical communication early in their academic careers. In fourth-year, students learn about engineering law and ethics. It is expected that students will apply these skills and knowledge throughout their academic program and beyond.

Standard 8 - UOIT faculty strive to include active learning methods to provide students with practical, hands-on learning of concepts. These include in-class exercises, tutorial exercises for further practice (such as skills in sketching and conceptualizing), laboratory sessions, and design-build projects in core and complementary engineering courses.

Standard 9 - UOIT's Faculty of Engineering and Applied Science has internationally renowned professors in their respective disciplines and is committed to hiring the best and most talented personnel. Faculty also have opportunities and resources to enhance their professional development, including through industrial partnerships that have been established through PACE (Partners for the Advancement of Collaborative Engineering Education).

Standard 10 - Faculty members in FEAS at UOIT have many opportunities to enhance their competency in teaching, including use of the Teaching and Learning Centre on campus, as well as participation in education symposiums through conferences and organizations such as Engineering and Product Design Education (EPDE) and ASME. FEAS strives to hire and maintain faculty that are also effective as instructors.

Standard 11 - FEAS faculty use a number of means to evaluate achieved learning outcomes, including written examinations, oral presentations, written assignments and reports, as well as peer and self assessment. A recently developed tool currently being used in the core engineering design courses (including capstone) and some complementary design courses specific to each field is the ICE rubric [19, 20], with application to evaluation of group term design projects to provide a fair and objective manner of assessing the level of learning and application of skills and knowledge pertaining to each respective project.

Standard 12 - Tools available to FEAS to evaluate their engineering programs include course evaluations, industry reviews, as well as accreditation evaluation and reporting. UOIT's engineering programs are continually assessed to ensure delivery of learning outcomes for students as required by major stakeholders.

\section{Conclusions}

UOIT's Mechanical Engineering program continues to develop and improve each year to ensure that it delivers the necessary learning outcomes sought by industry and accreditation boards. This paper 
examines the Mechanical Engineering program to see how close the content, facilities, and learning outcomes are to those of CDIO programs. The program, as it is today, complies very well with the CDIO standards. This characteristic can be attributed to many early implementations of learning methodologies, program and course content, and provision of modern facilities and technologies to complement academics, many of which have been established as a result of the NSERC-UOIT Senior Chair of Innovative Design Engineering's initiatives. A natural step for the Mechanical Engineering program to take is to firmly and officially have itself recognized as a CDIO program.

\section{Acknowledgements}

The authors would like to thank the Natural Sciences and Engineering Research Council (NSERC) of Canada and UOIT for financially supporting UOIT's Design Chair budget, part of which supported this research work. The authors are also grateful for the hardware and software provided by PACE (Partners for the Advancement of Collaborative Engineering Education).

\section{References}

[1] Kumar, V., Haapala, K. R., Rivera, J. L., Hutchins, M. J., Endres, W. J., Gershenson, J. K., Michalek, D. J., and Sutherland, J. W., "Infusing Sustainability Principles into Manufacturing/Mechanical Engineering Curricula," Journal of Manufacturing Systems, Vol. 24, No. 3, 2006, pp. 215-225.

[2] Brodeur, D. R., Crawley, E. F., Ingemarsson, I., Malmqvist, J., Östlund, S., "International Collaboration in the Reform of Engineering Education," American Society of Engineering Education Conference, Montreal, Canada, June 16-19, 2002. Session 2260.

[3] Gustafsson, G., Newman, D. J., Stafström, S., Wallin, H. P., "First-year Introductory Courses as a Means to Develop Conceive - Design - Implement Operate Skills in Engineering Education Programmes," Société Européenne pour la Formation des Ingénieurs (SEFI) Conference, Florence, Italy, September 8-11, 2002.

[4] Armstrong, P. J., Kee, R. J., Kenny, R. G., and Cunningham, G., "A CDIO Approach to the Final Year Capstone Project," 1st Annual CDIO Conference, Kingston, Ontario, June 7-8, 2005.

[5] Berggren, K., Brodeur, D., Crawley, E. F., Ingemarsson, I., Litant, W. T. G., Malmqvist, J., and Östlund, S., "CDIO: An International Initiative for Reforming Engineering Education," World
Transactions on Engineering and Technology Education, Vol. 2, No. 1, 2003, pp. 49-52.

[6] Crosthwaite, C., Cameron, I., Lant, P., and Litster, J., "Balancing Curriculum Processes and Content in a Project Centred Curriculum: In Pursuit of Graduate Attributes," Chemical Engineering Research and Design, Vol. 84, No. 7, July 2006, pp. 619-628.

[7] Abbas, A. and Romagnoli, J. A., "Curriculum Intensification Through Integration of Units of Study in the Chemical Engineering Degree Programme," Education for Chemical Engineers, Vol. 2, No. 1, 2007, pp 46-55.

[8] Jesweit, J., Duflou, J., Dewulf, W., Luttrop, C., and Hauschild, M., "A Curriculum for Life Cycle Engineering Design for the Environment," $1^{\text {st }}$ Annual CDIO Conference, Queen's University, Kingston, ON, June 7-8, 2005.

[9] Xiong, G. and Lu, X., "A CDIO Curriculum Development for the Program of Civil Engineering," $3^{\text {rd }}$ Annual CDIO Conference, MIT, Cambridge, MA, June 11-14, 2007.

[10] Gu, P., Shen, M., and Lu, X., "Curricular Reform Based on the CDIO Initiative in Shantou University," $3^{\text {rd }}$ Annual CDIO Conference, MIT, Cambridge, MA, June 11-14, 2007.

[11] Poblete, P. V., Vargas, X., Celis, S., Gazmuri, P., Bilbao, J., and Brodeur, D., "Curriculum Renewal at Two Universities in Chile Using the CDIO Syllabus," Annual CDIO Conference, MIT, Cambridge, MA, June 11-14, 2007.

[12] Vũ, D. A. and Phùng, N. X., "Adapting the CDIO Approach in Developing Learning Outcomes for Economics and Business Disciplines in Vietnam: A Case-Study of University of Economics and Business at Vietnam national University, Hanoi," $6^{\text {th }}$ Annual CDIO Conference, École Polytechnique, Montréal, QC, June 15-18, 2010.

[13] Larsson, J., “'Communication of Mathematics' as a Tool to Improve Students' General Communicative Skills," $3^{\text {rd }}$ Annual CDIO Conference, MIT, Cambridge, MA, June 11-14, 2007.

[14] Crawley, E. F., "The CDIO Syllabus: A Statement of Goals for Undergraduate Engineering Education," Department of Aeronautics and Astronautics, Massachusetts Institute of Technology, January 2001.

[15] Crawley, E. F., "Creating the CDIO Syllabus, A Universal Template for Engineering Education," $32^{\text {nd }}$ ASEE/IEEE Frontiers in Education Conference, Boston, MA, November 6-9, 2002. 
[16] "World Wide CDIO Initiative Standards," January 2004. HTTP:

http://www.cdio.org/implementing-cdio-your-

institution/standards.

[17] "Engineering Internship Program," HTTP:

http://www.engineering.uoit.ca/undergraduate/internsh ip/internship.

[18] "Engineering Coop Program," HTTP:

http://www.engineering.uoit.ca/undergraduate/internsh ip/coop.

[19] Platanitis, G. and Pop-Iliev, R., "Establishing Fair Objectives and Grading Criteria for Undergraduate Design Engineering Project Work: An Ongoing Experiment," International Journal of Research and Reviews in Applied Sciences, Vol. 3, No. 5, December 2010, pp. 271-288.

[20] Platanitis, G., Pop-Iliev, R., and Nokleby, S., "Implementation and Effect of Rubrics in Capstone Design Courses," Proceedings of the ASME 2009 International Design Engineering Technical Conferences \& Computers and Information in Engineering Conference (IDETC/CIE), San Diego, CA, August 30-September 2, 2009. Paper No.: DETC2009-86996. 